\title{
INVESTIGASI EXPERIMENTAL KONDUKTIVITAS PANAS PADA BERBAGAI LOGAM
}

\author{
SRI WURYANTI* DAN PURWINDA IRIANI \\ Departemen Teknik Konversi Energi Politeknik Negeri Bandung \\ Jln. Gegerkalong Hilir, Ds. Ciwarga, Bandung 40012, Jawa Barat \\ * email : sriwuryanti.lamda@gmail.com
}

\begin{abstract}
Abstrak. Teknologi material dibutuhkan untuk meningkatkan performance suatu alat, terutama alat-alat mekanik dan listrik. Salah satu penerapannya yakni pada HE, pipa-pipa distribusi uap, furnace, tangki pemanas dan sebagainya. Nilai konduktivitas yang kecil biasanya digunakan untuk bahan isolator, sedangkan nilai yang besar untuk konduktor. Konduktivitas panas pada setiap material mempunyai nilai yang berbeda-beda dan pada umumnya bahan padat lebih tinggi daripada cairan. Jumlah laju perpindahan panas mempunyai nilai yang tinggi, apabila nilai konduktivitas panasnya besar. Untuk dapat mengukur nilai konduktivitas panas diperlukan alat pengukuran yang representatif dan disini akan dibuat rangkaian peralatan yang terdiri dari Joulemeter, thermometer digital dan powersupply. Dari hasil pengukuran diperoleh nilai konduktivitas panas untuk alumunium $74,829 \mathrm{~W} / \mathrm{m}^{\circ} \mathrm{C}$ sampai $160,348 \mathrm{~W} / \mathrm{m}{ }^{\circ} \mathrm{C}$, baja $61,862 \mathrm{~W} / \mathrm{m}{ }^{\circ} \mathrm{C}$ sampai 83,987 $\mathrm{W} / \mathrm{m}^{\circ} \mathrm{C}$, besi $64,619 \mathrm{~W} / \mathrm{m}^{\circ} \mathrm{C}$ sampai $85,924 \mathrm{~W} / \mathrm{m}^{\circ} \mathrm{C}$, untuk besi tempa $41,143 \mathrm{~W} / \mathrm{m}{ }^{\circ} \mathrm{C}$ sampai $74,253 \mathrm{~W} / \mathrm{m}^{\circ} \mathrm{C}$ dan seng $57,094 \mathrm{~W} / \mathrm{m}^{\circ} \mathrm{C}$ sampai $80,289 \mathrm{~W} / \mathrm{m}{ }^{\circ} \mathrm{C}$.
\end{abstract}

Kata kunci : HE, Isolator, Joulemeter, Power supply, Thermometer digital

\begin{abstract}
Material technology is needed to improve the performance of a device, especially mechanical and electrical equipments. One of its applications is in HE, steam distribution pipes, furnaces, heating tanks and so on. Small thermal conductivity values are usually used for insulating materials, while the values are great for conductors. The thermal conductivity of each material has different values and in general, solids are higher than liquids. The amount of heat transfer rate has a high value, if the thermal conductivity value is large. To be able to measure the value of thermal conductivity is required a representative measurement tool and here will be made a series of equipment consisting of Joulemeter, digital thermometer and power supply. From the measurement results obtained the value of themal conductivity for aluminum $74,829 \mathrm{~W} / \mathrm{m}{ }^{\circ} \mathrm{C}$ to $160,348 \mathrm{~W} / \mathrm{m}$ ${ }^{\circ} \mathrm{C}$, steel $61,862 \mathrm{~W} / \mathrm{m}^{\circ} \mathrm{C}$ to $83,987 \mathrm{~W} / \mathrm{m}^{\circ} \mathrm{C}$, iron $64,619 \mathrm{~W} / \mathrm{m}^{\circ} \mathrm{C}$ to $85,924 \mathrm{~W} / \mathrm{m}^{\circ} \mathrm{C}$, for wrought iron $41,143 \mathrm{~W} / \mathrm{m}^{\circ} \mathrm{C}$ to $74,253 \mathrm{~W} / \mathrm{m}^{\circ} \mathrm{C}$ and zinc $57,094 \mathrm{~W} / \mathrm{m}{ }^{\circ} \mathrm{C}$ to $80,289 \mathrm{~W} / \mathrm{m}$ ${ }^{\circ} \mathrm{C}$.
\end{abstract}

Keywords : HE, Insulator, Joulemeter, Power supply, Digital thermometer

\section{Pendahuluan}

Karakteristik material yang berhubungan dengan termal sangat menentukan keberhasilan jumlah panas yang dipindahkan atau jumlah panas yang berhasil diisolasi yang dikenal dengan istilah konduktivitas panas. Nilai konduktivitas panas (k) adalah salah satu variabel di dalam persamaan perpindahan panas konduksi. Konduktivitas panas tersebut nilainya antara satu material dengan material lainnya berbeda-beda. Nilai konduktivitas panas terbesar untuk logam adalah alumunium yakni $200 \mathrm{~W} / \mathrm{m}^{\circ} \mathrm{C}$ [1] dan terkecil adalah nano partikel $10 \%$ vol CuNWs [2]. 
Sedangkan untuk memperoleh laju perpindahan panas yang makin besar diperlukan material dengan nilai konduktivitas lebih besar.

Penerapan perpindahan panas di indusri proses, banyak menggunakan HE, pipapipa distribusi uap, furnace, tangki pemanas dan sebagainya, dimana semua peralatan tersebut membutuhkan material yang berhubungan dengan konduktvitas panas. Oleh karena itu diperlukan kemampuan dalam menguji nilai konduktivitas panas suatu material, agar bisa memilih material yang paling tepat untuk diterapkan pada peralatan tertentu.

Pada saat ini di Indonesia jarang yang mempunyai alat untuk mengukur konduktivitas panas, untuk itu, akan dibuat sistem pengukuran yang terdiri dari sumber tegangan, termometer digital, dan Joulemeter. Dengan merangkai komponen-komponen tersebut membentuk sistem pengujian, dilakukan kalibrasi system peralatan, selanjutnya melakukan serangkaian pengujian untuk mendapatkan nilai konduktivitas panas berbagai material.

\subsection{Konduksi melalui plat}

Di dalam perhitungan konduksi ini, persamaan yang digunakan untuk konduksi yang terjadi pada plat adalah:

$$
\mathrm{q}=\frac{\mathrm{k} \times \mathrm{A} \times\left(\mathrm{T}_{1}-\mathrm{T}_{2}\right)}{\left(\mathrm{x}_{2}-\mathrm{x}_{1}\right)}
$$

Dimana q adalah laju perpindahan panas (W); k, konduktivitas panas $\left(\mathrm{W} / \mathrm{m}^{\circ} \mathrm{C}\right) ; \mathrm{A}$, luas perpindahan panas $\left(\mathrm{m}^{2}\right) ;\left(\mathrm{x}_{2}-\mathrm{x}_{1}\right)$, tebal material $(\mathrm{m}) ;\left(\mathrm{T}_{1}-\mathrm{T}_{2}\right)$, perubahan suhu $\left({ }^{\circ} \mathrm{C}\right)$.

\subsection{Konduksi melalui silinder radial}

Konduksi melalui silinder radial yang mempunyai jari-jari dalam dan jari-jari luar, sehingga persamaan yang digunakan untuk konduksi yang terjadi pada pipa atau silinder radial adalah:

$$
\mathrm{q}=\frac{\mathrm{k} \times \mathrm{A} \times\left(\mathrm{T}_{1}-\mathrm{T}_{2}\right)}{\left(\mathrm{x}_{2}-\mathrm{x}_{1}\right)}
$$

Dimana q adalah laju perpindahan panas $(\mathrm{W}) ; \mathrm{k}$, konduktivitas panas $\left(\mathrm{W} / \mathrm{m}^{\circ} \mathrm{C}\right) ; \mathrm{A}$, luas perpindahan panas $\left(\mathrm{m}^{2}\right) ; \mathrm{r}_{\mathrm{o}}, \mathrm{r}_{\mathrm{i}}$,jari-jari pipa luar dan jari-jari pipa dalam $(\mathrm{m})$; $\left(T_{1}-T_{2}=\right.$ perubahan suhu $\left({ }^{\circ} \mathrm{C}\right)$.

Nilai konduktivitas panas berbeda-beda, nilai tertinggi untuk logam, yang sedang untuk non logam dan yang terendah zat cair. Dalam rangka penghematan energy yang murah, salah satunya adalah dengan mengisolasi pipa diatribusi energy baik energy berupa uap, panas surya maupun listrik.

\section{Metode Penelitian}

Perancangan dan pembuatan alat pengukuran konduktivitas panas, dengan merangkaikan sumber tegangan ke Joulemeter, kemudian Joulemeter dihubungkan dengan power supply. Dari Joulemeter diperoleh nilai laju perpindahan panas, 
setelah material yang akan diuji dihubungkan dengan power supply. Material tersebut dijepit dengan suatu penjepit, dimana penjepit tersebut dihubungkan dengan 2 buah termodigital, sehingga akan terukur beda temperaturnya. Dari hubungan beda temperature, nilai laju perpindahan panas dan ketebalan material, akan diperoleh nilai konduktivitas panas.

Pengujian alat pengukuran konduktivitas panas dilakukan dengan berbagai material logam baik dalam bentuk plat maupun dalam bentuk silinder radial. Pengujian seng, alumunium, dan baja berbentuk plat dengan variasi waktu 60, 75, 90, 105, 120, 135, 150, 160 dan 180 detik. Pengujian besi, besi tempa dan baja berbentuk silinder dengan variasi waktu 60, 75, 90, 105, 120, 135, 150, 160 dan 180 detik.

Hasil pengujian akan diperoleh data-data: beda temperature, laju perpindahan panas, dan pengukuran luas perpindahan panas. Dari data-data tersebut akan dianalisa dengan menerapkannya pada persamaan konduksi, hasil pengukuran nilai konduktivitas panas dibandingkan dengan nilai hasil penelitian yang telah diterbitkan didalam jurnal atau dari tabel. Berikut adalah diagram alir pembuatan konsep dari awal pembuatan sampai pengambilan data:

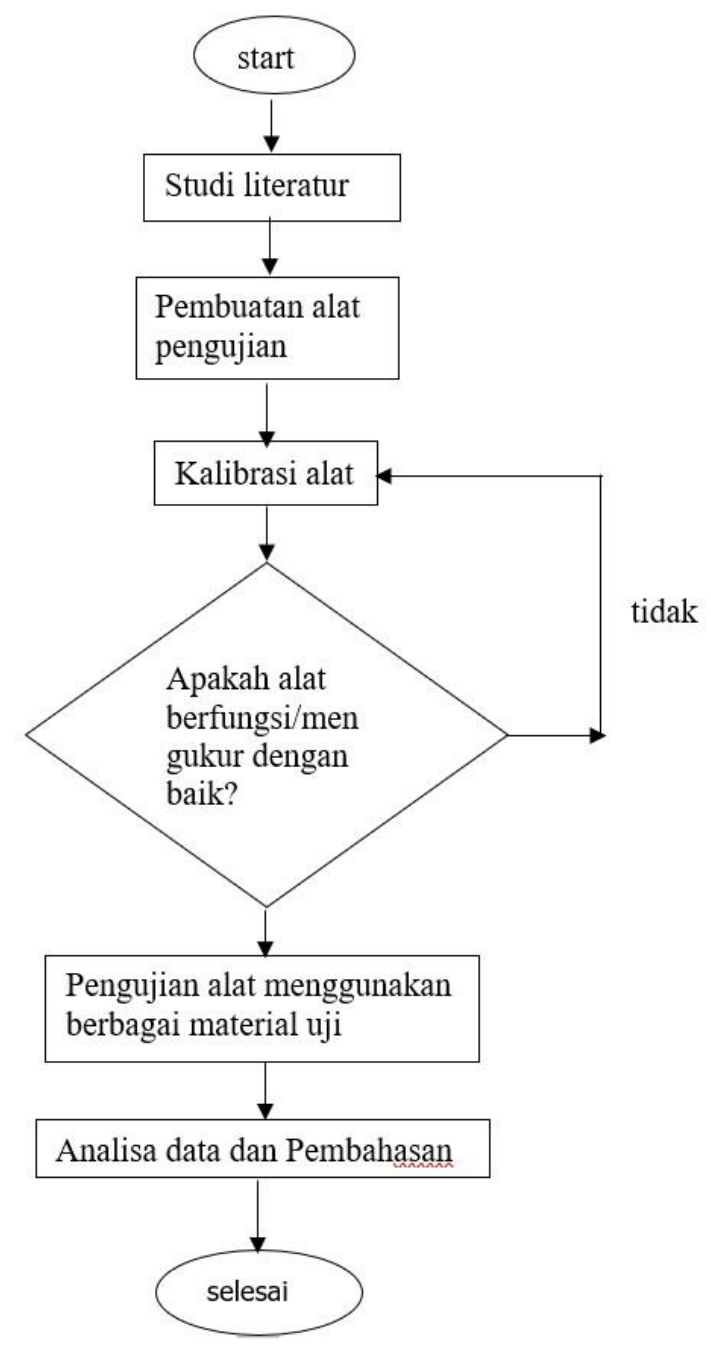

Gambar 1. Diagram alir metode penelitian 


\section{Hasil dan Pembahasan}

Dari hasil pengujian diperoleh data-data temperatur yang terukur pada thermometer digital yakni $\mathrm{T}_{1}$ dan $\mathrm{T}_{2}$ dan jumlah panas (q) yang dipindahkan dari satu sisi plat ke sisi plat lainnya (untuk logam dalam bentuk plat). Sedangkan untuk logam dalam bentuk pipa, diperoleh jumlah panas yang dipindahkan dari bagian dalam pipa (diameter dalam pipa) ke bagian luar pipa (diameter luar pipa). Hasil perhitungan menggunakan persamaan (1) dan (2), yakni dengan memasukkan beda temperature dari $T_{1}$ dan $T_{2}$ dan $q$, serta luas perpindahan panas untuk plat. Sedangkan untuk pipa, dengan cara yang sama, tetapi luas perpindahan panas dihitung dengan memasukkan nilai jari-jari dalam dan jari-jari luar, sehingga diperoleh harga konduktivitas panas seperti yang digambarkan pada Gambar 2 sampai Gambar 6.

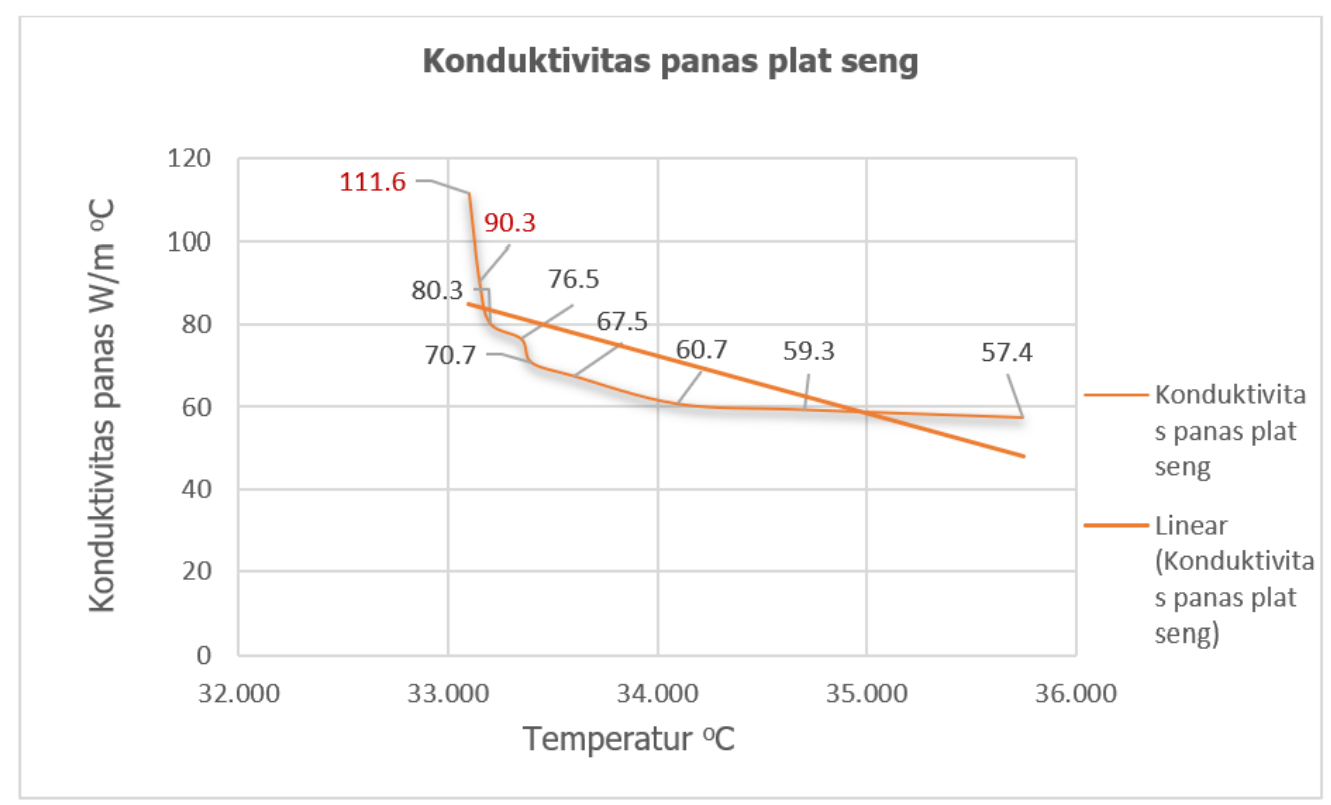

Gambar 2. Grafik hubungan antara temperature vs konduktivitas panas plat seng

Nilai konduktivitas panas plat seng pada temperatur $33^{\circ} \mathrm{C}$ yakni $111,6^{\circ} \mathrm{C}$ berbeda dengan yang ditabelkan oleh Holman yakni $111,1 \mathrm{~W} / \mathrm{m}^{\circ} \mathrm{C}$ [1], jadi terjadi perbedaan sebesar 0,4 \%. Tetapi terdapat kesesuaian antara hasil pengukuran terhadap penelitian oleh peneliti lain, yakni kecenderungan temperature semakin naik dengan nilai konduktivitas yang semakin turun.

Nilai konduktivitas panas plat baja pada temperature $30,5^{\circ} \mathrm{C}$ yakni $67,1 \mathrm{~W} / \mathrm{m}^{\circ} \mathrm{C}$ berbeda dengan yang didapatkan dari hasil penelitian Jonšta yakni $67,9 \mathrm{~W} / \mathrm{m}^{\circ} \mathrm{C}$, jadi terjadi perbedaan sebesar $1,17 \%$ [3]. Tetapi terdapat kesesuaian antara hasil pengukuran terhadap penelitian Jonšta, yakni kecenderungan temperature semakin naik dengan nilai konduktivitas yang semakin turun. 


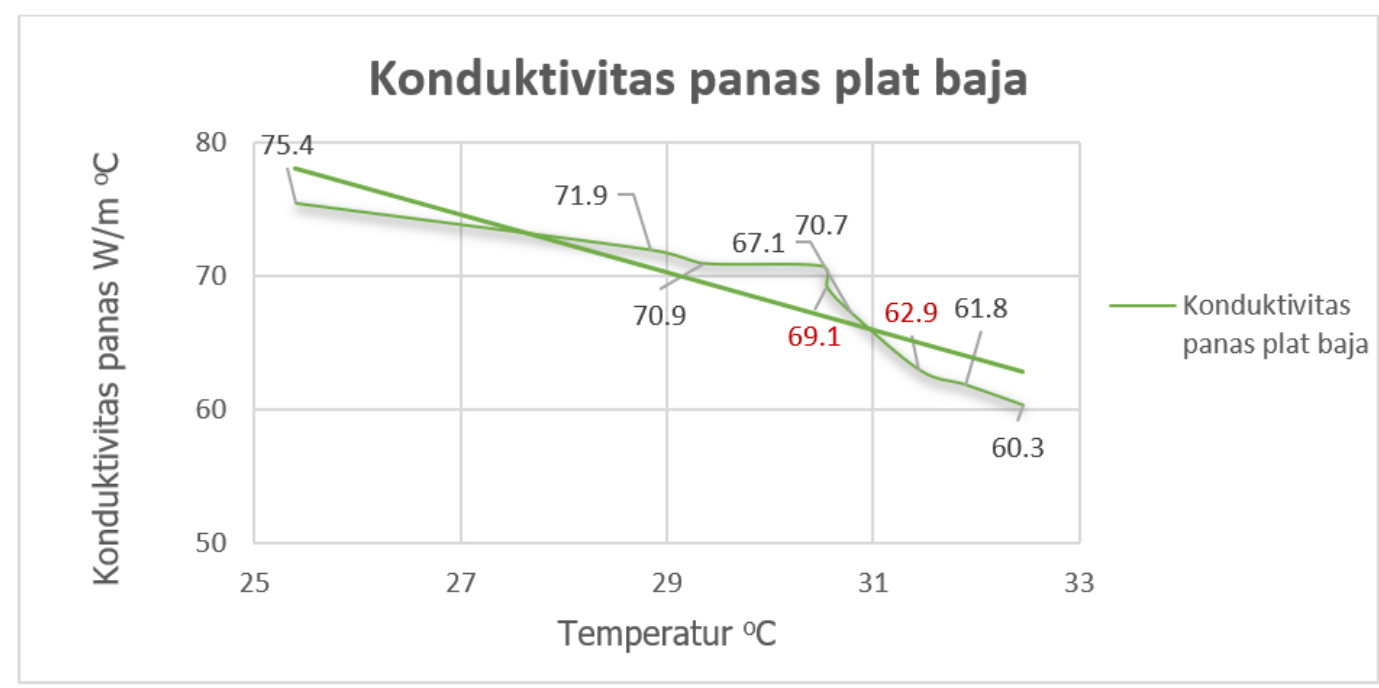

Gambar 3. Grafik hubungan temperature vs konduktivitas panas plat baja

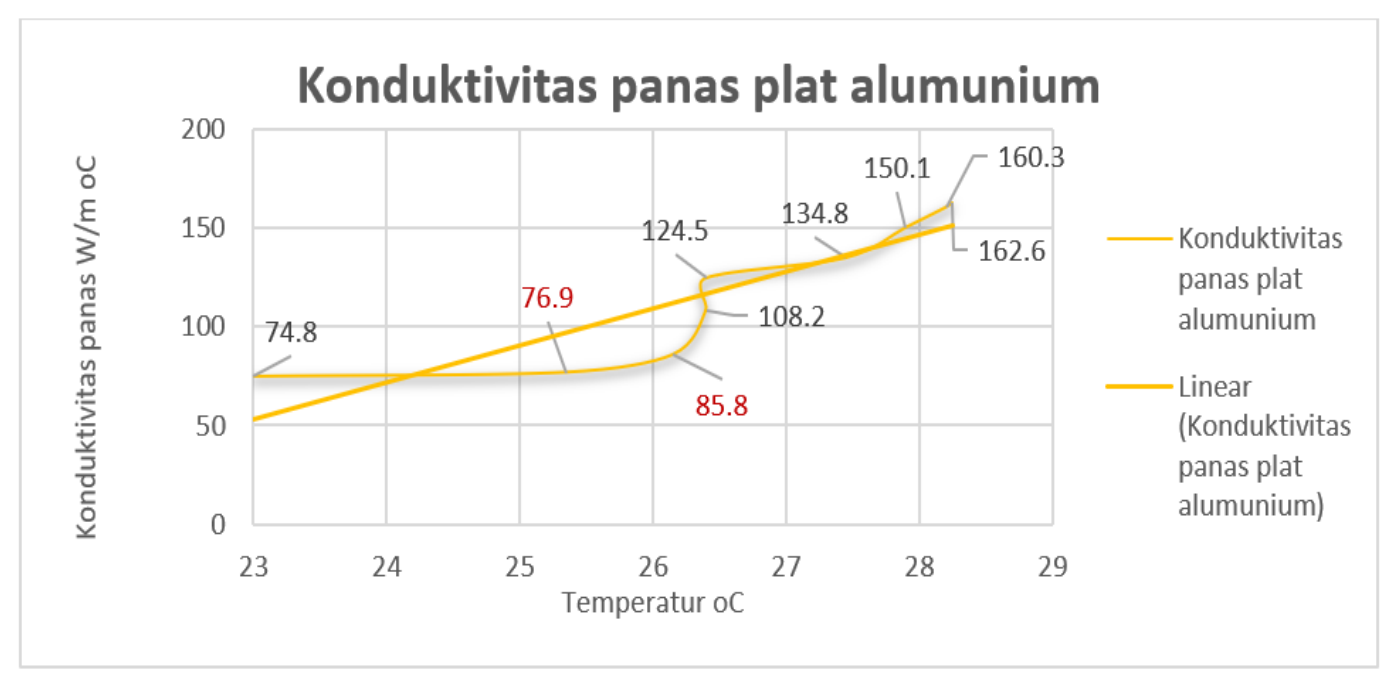

Gambar 4. Grafik hubungan temperature vs konduktivitas panas plat alumunium

Nilai konduktivitas panas plat alumunium dari hasil pengukuran sebesar $76 \mathrm{~W} / \mathrm{m}^{\circ} \mathrm{C}$ pada temperature $25^{\circ} \mathrm{C}$, terjadi perbedaan dengan hasil penelitian Elbara, yakni 80 $\mathrm{W} / \mathrm{m}^{\circ} \mathrm{C}$ [4]. Jadi terjadi penyimpangan sebesar 5\%. Tetapi mempunyai kecenderungan yang sama yakni dengan temperatur semakin naik, nilai konduktivitas panas juga semakin naik.

Nilai konduktivitas panas silinder radial besi dari hasil pengukuran pada temperature $33^{\circ} \mathrm{C}$ sebesar $73 \mathrm{~W} / \mathrm{m}^{\circ} \mathrm{C}$, terjadi perbedaan dengan hasil penelitian Elbara, yakni $70 \mathrm{~W} / \mathrm{m}^{\circ} \mathrm{C}$ [4]. Jadi terjadi penyimpangan sebesar $4,1 \%$. Tetapi mempunyai kecenderungan yang sama yakni dengan temperatur semakin naik, nilai konduktivitas panas juga semakin turun. 


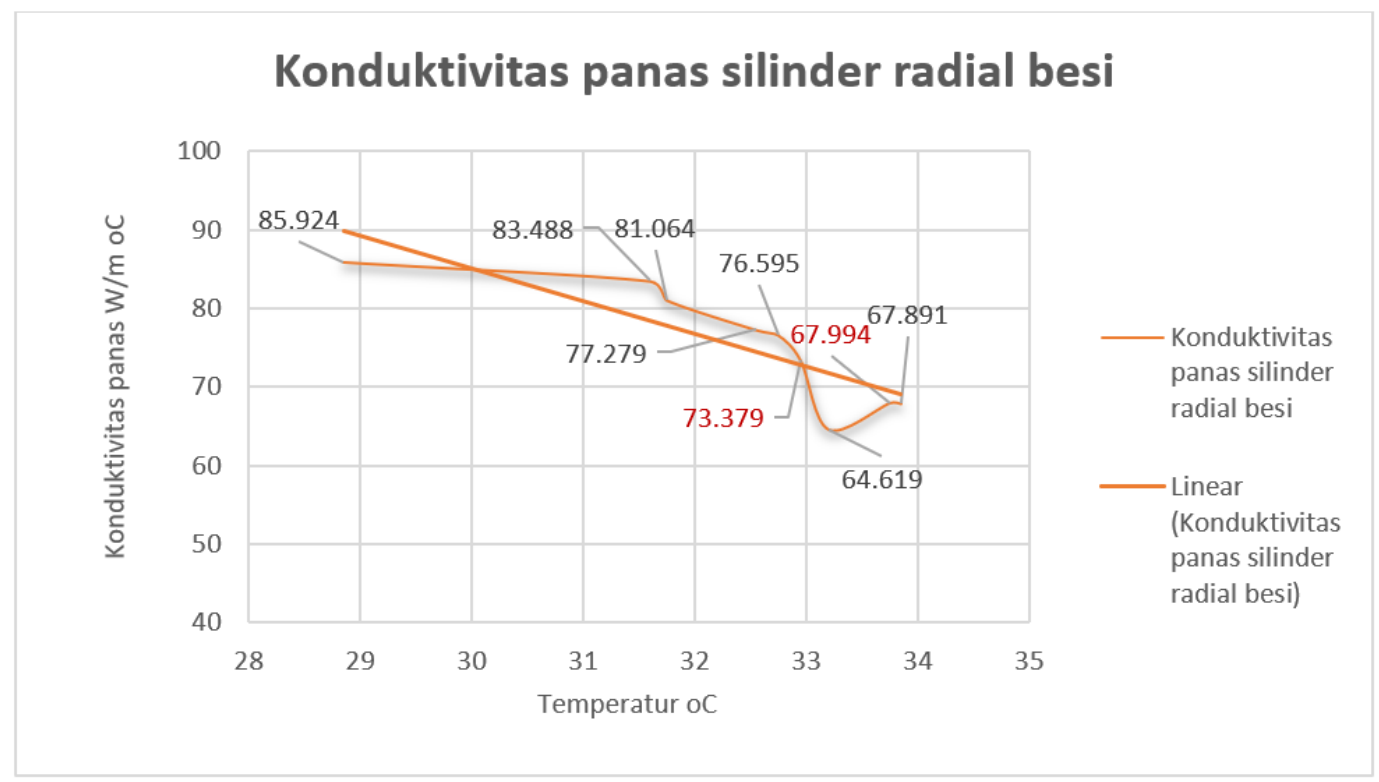

Gambar 5. Grafik hubungan temperature vs konduktivitas panas silinder radial besi

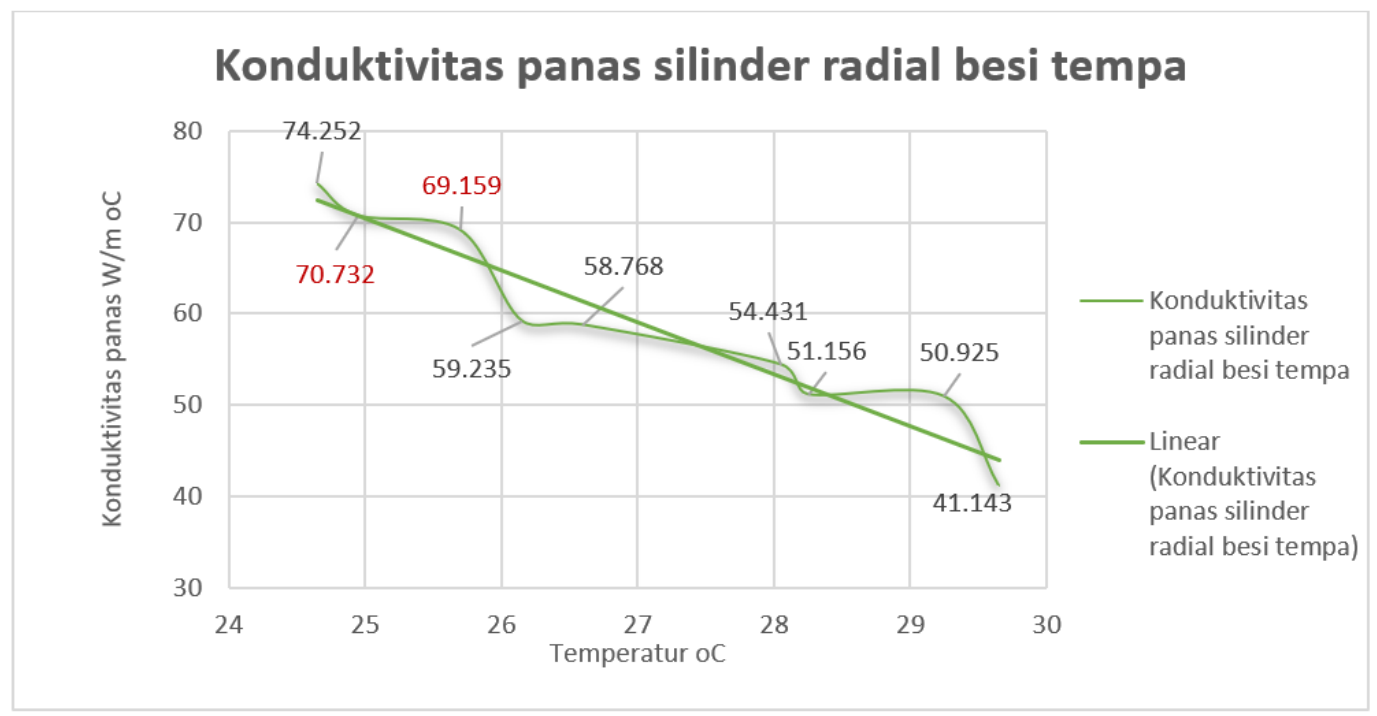

Gambar 6. Grafik hubungan temperature vs konduktivitas panas silinder radial besi tempa

Nilai konduktivitas panas silinder radial besi tempa dari hasil pengukuran pada temperature $25^{\circ} \mathrm{C}$ sama dengan yang ditabelkan oleh Holman, yakni $70 \mathrm{~W} / \mathrm{m}^{\circ} \mathrm{C}$ [1]. Begitu juga dengan kecenderungan temperatur yang semakin naik, nilai konduktivitasnya semakin turun.

Nilai konduktivitas panas silinder radial baja pada temperature $35^{\circ} \mathrm{C}$ yakni 71 $\mathrm{W} / \mathrm{m}^{\circ} \mathrm{C}$ berbeda dengan yang didapatkan dari hasil penelitian Jonšta, yakni 67,9 $\mathrm{W} / \mathrm{m}^{\circ} \mathrm{C}$ [3]. Disini terjadi perbedaan sebesar 4,36 \%. Tetapi mempunyai kecenderungan yang sama yakni dengan temperatur semakin naik, nilai konduktivitas panas juga semakin turun. 


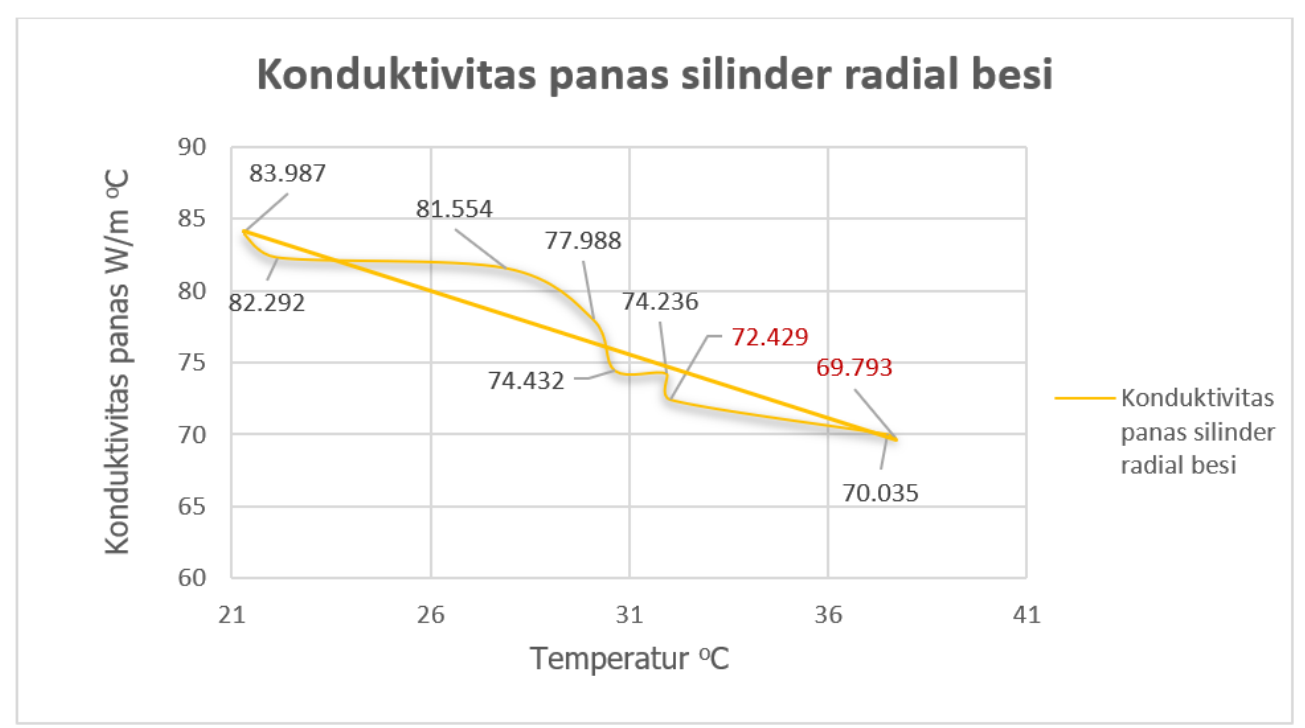

Gambar 7. Grafik hubungan temperature vs konduktivitas panas silinder radial baja

\section{Kesimpulan}

Nilai Konduktivitas panas yang terukur pada rangkaian peralatan yang dibuat terdapat perbedaan $0,4 \%$ sampai dengan $5 \%$ terhadap nilai hasil penelitian yang dilakukan oleh peneliti lain, kecuali pada pengukuran silinder radial besi tempa diperoleh nilai konduktivitas panas sebesar $70 \mathrm{~W} / \mathrm{m}^{\circ} \mathrm{C}$ pada suhu $25^{\circ} \mathrm{C}$. Hasil dari pengukuran yang tertinggi adalah logam alumunium yakni $160,348 \mathrm{~W} / \mathrm{m}^{\circ} \mathrm{C}$ pada suhu $28,3{ }^{\circ} \mathrm{C}$ dan terkecil logam besi tempa yakni $41,143 \mathrm{~W} / \mathrm{m}^{\circ} \mathrm{C}$ pada suhu 29,7 ${ }^{\circ} \mathrm{C}$.

\section{Ucapan terima kasih}

Penelitian ini dibiayai oleh DIPA POLBAN dalam rangka penambahan alat ukur konduktivitas panas untuk meningkatkan kapasitas laboratorium di Jurusan Teknik Konversi Energi. Alat ukur ini digunakan untuk praktek konduksi dalam mendukung kemampuan mahasiswa memahami salah satu mekanisme ilmu perpindahan panas.

\section{Daftar Pustaka}

1. J.P. Holman, Heat Transfer. New York: Mc. Graw-Hill, Companies Inc, tenth edition (2010).

2. D. Zhu, W. Yu, H. Du, L. Chen, Y. Li, H. Xie, Thermal Conductivity of Composite Materials Containing Copper Nanowires. Nanomaterials, College of Engineering, Shanghai Polytechnic University, Shanghai 09 (2016).

3. P. Jonšta, I. Vlčková, L'. Krišták, I. Špička, Z. Jonšta, Contribution to The Thermal Properties of Selected Steels. METALURGIJAVol. 54 (2015) p. 187-190.

4. E. Ziade1, J. Yang, T. Sato, P. Czubarow, A. Schmidt, Thermal Property Imaging of Alumunium Nitride Composites. Heat Transfer Vol. 137 No. 2 (2015). 